\title{
Profissionais de saúde frente ao aborto legal no Brasil: desafios, conflitos e significados
}

\author{
Health professionals and legal abortion in Brazil: \\ challenges, conflicts, and meanings
}

\footnotetext{
1 Coordenação Executiva do Cunhã Coletivo Feminista. Rua Projetada $s / n$,

Quadra 169, João Pessoa, $P B$ 58000-000, Brasil. gilbertas@ig.com.br
}

\begin{abstract}
This article discusses the roles of social workers, psychologists, nurses, and physicians concerning abortion and their participation in assisting legal abortion in Brazil for women victims of sexual violence. The working hypothesis was that many health professionals might oppose such programs on the grounds that they involve interruption of pregnancy. This qualitative study interviewed 12 health professionals and two program managers in the State of Paraiba and the Federal District (Brasilia). The health professionals' representations of abortion ranged from a moralist and religious concept to the promotion of women's rights and autonomy. The health professionals faced obvious challenges in dealing with the abortion issue. Their experience in treating women had fostered changes in values and a reinterpretation of the meaning of their own practice.
\end{abstract}

Key words Legal Abortion; Women's Health; Violence; Health Personnel

Resumo O objetivo deste artigo é compartilhar as representações de assistentes sociais, psicólogas, enfermeiras e médicos sobre o abortamento, com base em suas atuações nos programas de assistência às mulheres em situação de violência. O pressuposto inicial da pesquisa considerou a resistência de muitos profissionais em aderir aos programas, sobretudo, por causa da interrupção da gravidez. Tratou-se de um estudo qualitativo em que foram entrevistados 12 profissionais de saúde e dois gestores dos programas da Paraíba e do Distrito Federal. Os resultados da pesquisa revelaram que as representações dos profissionais sobre o abortamento transitaram de uma concepção mais moralista/religiosa à promoção dos direitos e da autonomia das mulheres. Foram evidentes os desafios com os quais os profissionais se depararam ao trabalhar com o tema do aborto. As experiências de atendimento às mulheres têm possibilitado mudanças de valores $e$ a resignificação da prática dos profissionais.

Palavras-chave Aborto Legal; Saúde da Mulher; Violência; Pessoal de Saúde 


\section{Introdução}

Este artigo pretende compartilhar as representações de assistentes sociais, psicólogos, enfermeiros e médicos sobre o aborto legal, com base na atuação desses profissionais de saúde na assistência ao abortamento previsto em lei.

No Brasil, a lei relativa ao abortamento é restritiva e refere-se à interrupção da gravidez resultante de estupro e de risco de vida da gestante. O abortamento previsto em lei, ou aborto legal, considera apenas estas duas exceções, previstas no Artigo 128 do Código Penal. Apesar dos referidos permissivos da lei terem sido incorporados desde 1940, apenas na década de 80 , foram realizados, oficialmente, os primeiros atendimentos no serviço público de saúde brasileiro. Os casos de anomalia fetal incompatível com a vida, apesar de não estarem contemplados nos permissivos da lei, também têm sido atendidos nos serviços de saúde, por meio de autorização judicial.

O primeiro serviço de atendimento ao abortamento previsto em lei foi implantado no Hospital Municipal Dr. Arthur Saboya, de São Paulo, em 1989. Na etapa inicial de implantação, os serviços se centraram na interrupção da gravidez, no entanto, com o cotidiano da assistência, o foco do atendimento foi deslocado para a atenção à violência sexual, ampliando e diversificando, dessa forma, a abrangência das ações de saúde.

Alguns fatores foram impulsionadores para a existência desse tipo de assistência no Brasil. Em primeiro lugar, a atuação do movimento feminista que durante anos tem discutido o abortamento no contexto dos Direitos Reprodutivos (Corrêa, 1999), reivindicando o direito da mulher de decidir sobre a interrupção da gravidez e que o Estado se responsabilizasse pela assistência aos casos de abortamento permitidos na lei.

Outro fator impulsionador, incluído na argumentação feminista, foi a realização da Conferência Internacional de População e Desenvolvimento (CIPD), no Cairo, em 1994, e da Conferência Mundial sobre a Mulher (CMM), em Pequim, 1995, que consolidaram os conceitos de direitos reprodutivos e direitos sexuais. O parágrafo 8.25 do relatório da CIPD diz que " nos casos em que o aborto não é contrário a lei, sua prática deve ser realizada em condições adequadas" (Araújo, 1999:57). Os países signatários desta Conferência se comprometeram em garantir a assistência ao abortamento nos casos previstos em lei e em melhorar a qualidade da assistência ao abortamento em geral.

Importante papel também teve a Federação Brasileira de Ginecologia e Obstetrícia (FEBRAS-
GO), que se comprometeu com a garantia do direito à interrupção da gestação dentro do marco legal e vem desenvolvendo, dentre outras ações, o Fórum Interprofissional sobre o Atendimento Integral à Mulher Vítima de Violência Sexual, cuja primeira versão aconteceu em parceria com o Centro de Pesquisa e Controle das Doenças Materno-Infantis de Campinas (CEMICAMP, 1997). O envolvimento da FEBRASGO tem contribuído, sobretudo, para a sensibilização e adesão dos médicos obstetras.

Finalmente, a iniciativa do Ministério da Saúde (MS, 1999), em adotar a Norma Técnica de Prevenção e Tratamento dos Agravos Resultantes da Violência Sexual contra Mulheres e Adolescentes foi importante para legitimar o atendimento ao aborto previsto em lei. A Norma Técnica além de orientar sobre os procedimentos, contribuiu para a aceitação e garantia da segurança dos profissionais de saúde na prática do abortamento previsto em lei.

A despeito dos elementos favoráveis, os diversos contextos políticos, influenciados pela moral vigente, criaram obstáculos à implantação da assistência ao abortamento previsto em lei e aos agravos resultantes da violência sexual nos estados brasileiros. Uma das dificuldades para a implantação dos serviços de atendimento ao aborto previsto em lei tem sido a de identificar profissionais de saúde disponíveis para atuar.

A assistência às mulheres vítimas de violência sexual, como uma ação de saúde, trouxe para o cotidiano dos serviços temas como o abortamento, a violência sexual e doméstica e as relações de gênero que se configuram como de difícil compreensão para os profissionais. Dentre outros motivos, o despreparo para lidar com estas questões esteve relacionado com a falta de capacitação e do conseqüente domínio de instrumental teórico e prático para tratar dos agravos resultantes da violência sexual, uma vez que este tema não faz parte da formação acadêmica dos profissionais de saúde, junto à crença de que esta não é uma problemática pertinente ao setor saúde (D'Oliveira \& Schraiber, 1999).

Diferentemente da violência sexual, o tema do abortamento faz parte do repertório de assuntos relacionados à vivência reprodutiva $\mathrm{e}$ está incluído na formação acadêmica dos profissionais da área médica e de enfermagem. Porém, a abordagem é influenciada por questões morais/religiosas que trazem dificuldades para a compreensão do tema. Geralmente, a assistência é norteada pela concepção de que o abortamento é um crime, sem referência aos direitos reprodutivos ou às questões sociais que derivam da problemática da clandestinidade. 
Os valores e posições contrárias dos profissionais de saúde ao abortamento aparecem quando se trata de atender mulheres em processo de abortamento incompleto, que chegam no serviço. Nestes casos, a conduta tem sido estritamente normativa e punitiva, caracterizando a trajetória desumana das mulheres nos serviços de saúde (Aguirre \& Urbina, 1997). A busca por um atendimento ao abortamento incompleto termina, muitas vezes, por se constituir em uma vivência marcada pelo desrespeito. São comuns os relatos de curetagem sem anestesia, negligências, maus-tratos, falta de orientação e atendimentos marcados por preconceitos. A pesquisa realizada no setor de abortamento de uma maternidade pública de João Pessoa apontou " padrões de crueldade, desconforto, violência e desumanização naturalizadas pelo atendimento à saúde na rede pública" (Cunhã Coletivo Feminista, 1997:29).

Cardich (1993) analisa que diante da obrigatoriedade de se atender a mulher que chega abortando, o profissional de saúde repassa para a usuária seu despreparo e preconceitos. Neste sentido, a indução ao abortamento aparece como uma dificuldade técnica, uma vez que o treinamento dos médicos é dirigido apenas para processos de abortamento que chegam aos serviços de saúde já iniciados.

Observa-se que a interrupção da gravidez por risco de vida no primeiro trimestre da gravidez encontra mais aceitação entre os médicos (Aguirre \& Urbina, 1997). O mesmo não acontece quando a interrupção é decorrente de estupro. O poder médico interdita ou referenda a prática do abortamento, facilitando ou criando impedimentos de acordo com o caso apresentado.

As representações dos profissionais e a compreensão do fenômeno da violência sexual e do direito ao abortamento no contexto da teoria de gênero se constituem elementos na definição da conduta e na interpretação e abordagem de cada caso (NESP, 1998)

Os estudos de Schraiber (Schraiber, 1997, Schraiber \& D'Oliveira, 1999) apontam a dificuldade dos profissionais de saúde em lidar com problemas da esfera social e da subjetividade humana, sobretudo aqueles com formação estritamente baseada no modelo biomédico. Essa dificuldade não se limita à inabilidade quanto às ações práticas, mas ao fato, de muitas vezes, não conseguirem visualizar os aspectos sociais e culturais relacionados aos problemas de saúde e a inabilidade de lidar com aspectos emocionais (Ribeiro Neto, 2000).

O objetivo do estudo foi entender a motivação, a resistência e a prática dos profissionais de saúde em relação ao aborto legal, considerando a interface com a violência sexual. O estudo busca contribuir para a implantação de serviços que atendam ao abortamento previsto em lei, por meio da compreensão da resistência de profissionais de saúde em trabalhar com o tema. O mesmo foi realizado na Paraíba e no Distrito Federal, com a equipe de saúde dos programas de assistência às mulheres em situação de violência.

\section{Breve história da implantação e caracterização dos serviços pesquisados}

O Programa de Assistência às Mulheres Vítimas de Violência Sexual da Paraíba foi implantado pela Portaria 335, datada de 15 de setembro de 1998, da Secretaria de Saúde do Estado da Paraíba (Paraíba, 1998).

A existência deste serviço foi resultado de um longo processo de reivindicação do movimento de mulheres que, durante quatro anos, desenvolveu ações em prol da sua implantação (Souza \& Araújo, 2002), em articulação com outros setores, incluindo movimentos sociais, organizações sindicais, partidárias e parlamentares.

A composição da equipe foi um dos maiores desafios para a implantação. Neste sentido, foram realizadas algumas ações que buscaram a adesão dos profissionais. Inicialmente, foram identificadas as profissionais da área social e de enfermagem, posteriormente, as médicas. A equipe é formada somente por mulheres, sendo duas assistentes sociais, uma psicóloga, duas médicas e uma enfermeira que foram treinadas em serviços de outros estados.

A interrupção da gestação é realizada até a 12a semana por meio dos procedimentos de indução por misoprostol, curetagem convencional e técnica de Aspiração Manual Intra- uterina (AMIU). Prescrevem a anticoncepção de emergência e não disponibilizam profilaxia para HIV.

De janeiro de 1999 a setembro de 2002, o Programa atendeu 161 casos, sendo que 96,9\% foram relativos à violência sexual, 2,5\% à malformação fetal e $0,6 \%$ a risco de vida. A idade das mulheres atendidas variou de 2 anos e 4 meses a 56 anos de idade. Do total de casos, $3,7 \%$ resultaram na interrupção da gravidez.

No Distrito Federal, o atendimento ao abortamento previsto em lei foi implantado em 1996, pela resolução da Secretaria de Saúde do Distrito Federal (Distrito Federal, 1996), criada por proposição do Conselho Municipal de Saúde, com base na reivindicação e pressão políti- 
ca do movimento de mulheres. A proposta foi encampada pela direção do serviço que assumiu a responsabilidade pela implantação.

A assistente social e a psicóloga decidiram participar do Programa e colaboraram na captação dos demais profissionais. Os integrantes da equipe foram capacitados no próprio serviço sob a responsabilidade da equipe de um Programa de outro estado. A equipe é composta por homens e mulheres.

À época das entrevistas, existiam um assistente social e dois obstetras disponíveis para o Programa. Nos casos de interrupção, o atendimento de enfermagem era feito por qualquer enfermeiro do Centro Obstétrico. A maternidade não contava com psicólogo para o Programa, encaminhando os casos necessários ao serviço de psicologia da Delegacia da Mulher.

A interrupção também ocorre até a 12a semana e o procedimento utilizado é a AMIU em todos os casos. É realizada a contracepção de emergência e não oferecem a profilaxia para o HIV.

No período de agosto de 1996 a dezembro de 2001, foram atendidas 191 mulheres, com idade variando entre 12 e 66 anos. Destas, 68,6\% eram maiores de 18 anos e $31,4 \%$ de 12 até 18 anos. Do total, $17,8 \%$ interromperam a gestação, sendo que deste percentual, $63,2 \%$ por motivo de estupro e $36,8 \%$ por risco de vida.

A porta de entrada do atendimento é a emergência obstétrica, onde a mulher recebe os atendimentos de enfermagem e médicos. Depois é encaminhada para o serviço social e daí para Delegacia da Mulher ou Instituto Médico Legal (IML). Caso necessário, o seguimento do atendimento é feito por intermédio de acompanhamento médico e/ou psicológico. Quando há presença de gravidez, o serviço social encaminha para o médico do programa, que avalia, juntamente com a equipe, se a interrupção da gestação se coaduna ao protocolo.

\section{Metodologia}

Tratou-se de um estudo qualitativo e exploratório que buscou as representações das diferentes categorias profissionais dos serviços que implantaram Programas de Assistência às Mulheres Vítimas de Violência Sexual na Paraíba e no Distrito Federal. Os critérios adotados para escolha destes serviços foram: tempo de implantação superior a dois anos, regularidade no atendimento e manutenção da demanda para interrupção da gravidez.

Foram entrevistados todos os profissionais diretamente envolvidos com os programas, sendo três assistentes sociais, duas psicólogas, três enfermeiras e quatro obstetras, totalizando 12: cinco da Paraíba e sete do Distrito Federal.

Visando a caracterizar os programas, entender as suas histórias de implantação e contextualizar a atuação dos profissionais nas suas instituições, foram entrevistados dois gestores, sendo uma mulher e um homem, diretamente responsáveis pela implantação dos programas e foi feita a análise documental de relatórios, portarias e normas.

Trabalhou-se com entrevistas semi-estruturadas, com roteiro prévio, que foram gravadas e transcritas por um técnico. As entrevistas buscaram informações a respeito da atuação e formação profissional e sobre como se deu a inserção dos profissionais nos programas. Foram levantadas as representações dos mesmos por meio das opiniões sobre os casos atendidos, sobre a violência sexual e suas nuances, o abortamento, os desafios e as dificuldades enfrentadas.

Na Paraíba, as entrevistas aconteceram entre outubro e novembro de 2001, em locais variados. Foi contratada e treinada uma entrevistadora para realizá-las, uma vez que havia proximidade da pesquisadora com a equipe. No Distrito Federal, as entrevistas foram realizadas em janeiro de 2002, na própria maternidade, pela pesquisadora.

Segundo Herzlich (1991:27), o estudo das representações se propõe a descortinar conteúdos implícitos ao eventualmente revelado, "busca sobretudo, evidenciar o código a partir do qual se elaboram significações ligadas às condutas individuais e coletivas".

Giami \& Veil (1997) consideram que o processo de construção das representações se constitui como um filtro diante das várias informações científicas e técnicas que os profissionais recebem e dos seus valores éticos e morais.

Com intuito de revelar as representações sobre o abortamento, foi feita a análise do material pela pesquisadora, sendo os discursos categorizados com base neste interesse. A leitura foi feita de forma transversal, por meio de análise temática e comparativa entre as representações das diferentes categorias profissionais dos dois serviços estudados. De modo complementar, foi realizada a leitura singular das entrevistas (Blanchet \& Gotman, 1992).

Para garantir a recomendação ética acerca do anonimato dos entrevistados, os mesmos foram identificados, neste artigo, apenas pela profissão, considerando a facilidade de identificá-los nos referidos programas.

Este estudo foi aprovado pelo Comitê de Ética de Pesquisa do Centro de Ciências da Saúde da Universidade Federal da Paraíba, em 12 de novembro de 2001 . 


\section{Discussão dos resultados}

A revisão de documentos e as entrevistas com os gestores resultaram no resgate da história da implantação e na caracterização dos serviços, a fim de situar as representações dos profissionais no contexto em que se construíram, descritas a seguir. Neste momento, serão apresentados os significados revelados pelos profissionais de saúde em relação ao abortamento.

\section{Revelando significados}

Do total de profissionais pesquisados, dois eram homens e dez eram mulheres. Foram dois psicólogos, três assistentes sociais, três enfermeiros e quatro obstetras, com faixa etária entre 36 e 59 anos. Do total, $50 \%$ consideraram-se de cor branca, $10 \%$ negra e $40 \%$ parda. Quanto à religião, 16,6 \% disseram não pertencer a nenhuma, 83,3\% declararam-se como pertencente a alguma religião e desse total, $30 \%$ não eram praticantes.

O corpo discursivo apontou para a concepção de que a violência sexual deve ser tratada no âmbito da assistência à saúde e que pode minimizar as conseqüências para a mulher. Mesmo com os desafios que os profissionais de saúde enfrentaram para cuidar de mulheres violentadas, o tema da violência teve maior aceitação que a interrupção da gravidez.

Lembrando que as representações dizem respeito a um determinado grupo social, devendo ser evitadas generalizações sobre os resultados (Herzlich, 1991), atentou-se para o fato de que essas representações estavam associadas a profissionais que passaram por capacitações, e que se inseriram numa rede de interlocução que tem garantido às mulheres o direito à interrupção da gravidez nos dois casos previstos em lei.

A representação do abortamento para os profissionais de saúde entrevistados oscilou entre a concepção da interrupção da gravidez como um direito, em contraposição ao valor religioso do abortamento como um pecado.

A idéia da interrupção da gravidez como um direito de escolha, "um direito da mulher como pessoa e cidadã" (enfermeira), se identificou com o discurso feminista que defende o abortamento como um direito reprodutivo, no âmbito dos direitos humanos. Ao mesmo tempo, o fato da mulher que sofreu violência sexual decidir pelo abortamento foi um argumento atenuante para o profissional de saúde que se eximiu da responsabilidade: "a decisão é da mulher, é um problema dela, não do profissional" (médico).
A decisão da mulher também foi justificada por causas externas como condições econômicas e sociais. Este argumento tanto ampliou a compreensão, inserindo o abortamento nas realidades de cada mulher, quanto deslocou a escolha para fatores externos, como a sociedade, o governo, as condições econômicas, uma patologia.

"Eu acho que a gente deve olhar para a mulher que fez um aborto, sempre vendo as causas... Eu não conheço nenhuma mulher que depois que faz o aborto diga: 'ah, eu abortei!' com felicidade. Então, não podemos pensar que ela fez porque gosta de fazer crime, de fazer aborto... porque quando se incrimina a mulher é porque se acha que ela gostou de fazer" (médico).

O depoimento acima contém a única referência à criminalização que apareceu no corpo discursivo. No geral, a idéia de que o abortamento é um processo sofrido para as mulheres não apareceu associada à clandestinidade. No entanto, o peso moral, a exposição ao risco e a vulnerabilidade da situação de criminalidade interferem na forma como as mulheres vivem e sentem o processo do abortamento, haja vista as perigosas, inacessíveis e complexas formas de interromper uma gravidez (Germain \& Kim, 1999).

A concepção de que a interrupção é um direito, foi contraposta ao valor religioso do aborto como um pecado que produz culpa na mulher e no profissional que se comprometeu com o procedimento. Mais de metade dos profissionais que tinham vinculação religiosa ou nutriam concepções espirituais revelaram uma representação do abortamento mais relacionada à culpa, ao sofrimento e ao pecado.

"Da maneira como a gente foi criada, eu sabia que era pecado, a mulher que fazia isso não ia para o céu... mesmo que eu já tivesse dentro de mim que não era pecado, que não era nada, mas tinha aquela coisa que foi construída na minha vida do interior" (enfermeira).

O conflito foi um elemento presente nos profissionais de saúde que se depararam entre estar atuando nos programas, o comprometimento com a assistência, a pressão externa e a carga da influência religiosa. Em alguns discursos, encontrou-se ambigüidade nas representações, quando o mesmo profissional compreendeu o abortamento das duas formas já citadas.

A despeito das concepções e restrições religiosas pessoais, os profissionais das diversas categorias foram unânimes em afirmar que devem manter uma postura neutra e imparcial a respeito da decisão da mulher, não devendo julgá-la porque fez aborto. “O profissional não deve persuadir para fazer ou deixar de fazer o 
aborto" (médica). A contradição apareceu no decorrer do depoimento do profissional que disse que "decidiu por ficar no Programa para ajudar as mulheres a não fazer a interrupção" (médica).

Alguns profissionais temeram ser julgados pela sociedade, serem tachados de "aborteiros" e legalmente incriminados pela interrupção, como já constataram outros estudos (NESP, 1998). Este temor foi confirmado pelas pressões externas e cobranças recebidas principalmente dos colegas de trabalho, mencionado, sobretudo, pelos profissionais do Programa da Paraíba que se referiram às abordagens e "aos olhares de recriminação dos colegas” (enfermeira). As tensões criadas entre os profissionais e, sobretudo, aquelas advindas da categoria médica, atuaram como pressão contra aqueles que se interessaram em aderir ao Programa.

\section{Classificações, representações e condutas}

No âmbito da legalidade, o motivo que ocasionou o abortamento tornou-se importante para o significado atribuído pelo profissional que percebeu diferentemente a interrupção da gravidez em cada um dos casos.

No abortamento por risco de vida da mulher é o médico quem decide, deslocando a decisão da mulher para a indicação médica, amenizando o sentimento em relação à interrupção da gravidez, conforme mostraram estudos anteriores (Aguirre \& Urbina, 1997). Neste caso, o poder médico (NESP, 1998), referendou a prática do abortamento, minimizando ou retirando impedimentos presentes quando a gravidez é decorrente de estupro.

$\mathrm{O}$ aborto resultante de anomalia fetal incompatível com a vida foi mais fácil de ser aceito, pois foi associado ao princípio da medicina em salvar a vida, "como não envolve vida, não é um problema médico" (médico).

$\mathrm{O}$ abortamento resultante de estupro apareceu como uma decisão voluntária da mulher, considerado, pelos profissionais, o caso mais difícil de ser enfrentado pelas mulheres. A ênfase na dificuldade das mulheres revelou os significados e as dificuldades dos próprios profissionais. Essa forma de lidar com o aborto resultante de estupro, muitas vezes, expressa o descrédito à palavra da mulher e a desconfiança quanto à sua responsabilidade no estupro (Drezett, 2000). Esta concepção interfere na credibilidade conferida à história relatada pela usuária e, conseqüentemente, na decisão da equipe de que a interrupção seja pertinente ao protocolo do Programa. Houve um sentimento de indignação com a violência e com o agres- sor, assim como a expectativa de que a mulher fosse capaz de superar o sofrimento, tivesse o filho e o encaminhasse para a adoção.

\section{Então, por que se envolver?}

Considerando tantas nuances, conflitos internos, pressões e dificuldades para lidar com o abortamento, por que então esses profissionais se envolveram com a assistência ao aborto previsto em lei? Foram reveladas algumas motivações, expostas a seguir.

\section{- Questão legal}

Os profissionais se referiram ao fato de estarem atendendo a uma determinação superior e se sentiram protegidos por estarem "amparados pela lei” (médica). Essa representação relacionou-se com a ilegalidade do abortamento, sendo importante o surgimento de mecanismos legais que protegessem a ação do profissional.

\section{- Questão técnica}

A questão da atribuição profissional apareceu como um fator importante. Houve a explicitação do sentimento de segurança técnica baseada no domínio dos procedimentos. Este tipo de atendimento foi considerado como parte do rol de responsabilidades da área médica e de enfermagem: “...o estupro, a violência sexual atingem os órgãos que fazem parte da minha especialidade..." (médico). Esta postura modelou a forma de se relacionar com a usuária: " $a$ gente não se envolve com a história, com o sentimento da mulher, mantém distância" (enfermeira) e apareceu como uma solução para o profissional poder conviver com as mulheres em processo de abortamento. Percebeu-se, portanto, que a questão se "revela não só como técnica cientificamente armada, mas técnica moral dependente" (Schraiber, 1997:132), dada a complexidade de julgamento e aos riscos inerentes à decisão médica. Schraiber (1997) adverte que a incerteza intrínseca à técnica torna premente a ética nas decisões médicas.

\section{- Motivação altruísta}

Participar do Programa de Assistência às $\mathrm{Mu}$ lheres Vítimas de Violência Sexual fez parte do desejo de ser útil, de ser solidário com pessoas que estão em sofrimento, como referiu a assistente social: "é questão de você poder ajudaro ser humano naquilo que ele necessita, e que existe a lei e ela tem de ser cumprida naquilo que ela procura" (assistente social). 


\section{- Direitos da mulher}

Houve uma identificação com a causa feminina, com a solidariedade e garantia dos direitos das mulheres. Esta identificação garantiu o comprometimento pessoal e profissional e foi um requisito importante para o atendimento humanizado. Alguns profissionais tiveram contato com grupos feministas e participaram de processos formativos: "eu sempre fui uma pessoa que sempre pensei muito pelo lado da mulher, se ela não quer, porque continuar com aquele filho?" (enfermeira).

\section{- Vivência pessoal e/ou profissional}

Apareceram motivações relacionadas à própria vivência diante da violência sexual, ou a de alguém próximo, e outras relacionadas ao cotidiano profissional em que as seqüelas da violência sexual apareceram nos ambulatórios, salas de parto ou consultórios particulares.

\section{Quebrando as resistências}

O relato da vivência dos profissionais mostrou como o envolvimento dos mesmos com a assistência provocou enfrentamentos e repercussões nos seus valores e comportamento. Consideraram-se mais abertos, revendo concepções a respeito do abortamento e da violência sexual. "Mudou, mudou, porque hoje eu já não sou contra, encaro numa boa a questão do aborto, fico lá, acompanho a paciente se eu estiver por perto, sem nenhum constrangimento" (assistente social). O cotidiano da assistência trouxe repercussões para a ética de cada um, aproximando os profissionais da história e dos sentimentos das mulheres.

Participar dos programas representou a oportunidade de crescimento pessoal e profissional, melhorando o acesso a informações, possibilitando viagens, intercâmbios, cursos, dar palestras e entrevistas na mídia. Também conferiu status ao profissional: “...isso tudo é uma forma de aprendizado, porque você tem que se doar naquele programa" (psicóloga).

\section{Considerações finais}

A fala dos profissionais de saúde envolvidos na assistência ao abortamento previsto em lei sinalizou a complexa rede de desafios que se colocaram para eles. Devido ao reduzido número de artigos sobre este tema, este trabalho tornase importante ao revelar as representações dos profissionais a respeito do abortamento.

Os profissionais se depararam e interagiram com diversos elementos como a hierarquia do trabalho da equipe de saúde, a emergência de conflitos internos, a influência religiosa e determinação jurídica, o comprometimento com a assistência, a solidariedade e o desejo de crescimento.

A visão dinâmica das representações possibilitou a expressão das várias significações colocadas em campos opostos e por isso conflitantes, que muitas vezes coexistiram na mesma pessoa. As representações quebraram a visão monolítica do discurso e trouxeram à tona a rica dinâmica de relação entre valores e significados. As dimensões técnicas, legais e éticas explicaram os motivos que levaram à adesão dos profissionais. Ao mesmo tempo em que acreditaram estar fazendo algo correto técnica e eticamente (a decisão pelo abortamento como um direito humano), compartilharam de uma matriz cultural que coloca o abortamento como uma questão moral/religiosa.

É importante ressaltar que as experiências de atendimento às mulheres em situação de violência sexual provocaram possibilidades de mudança dos valores e a resignificação da prática dos profissionais de saúde. A experiência e o convívio com as mulheres e suas histórias de dor e sofrimento transformaram resistência, medo e distância em solidariedade e compromisso. 


\section{Referências}

AGUiRRE, D. G. L. \& URBINA, A. A. S., 1997. Los médicos en formación y el aborto: Opinión de estudiantes de medicina en la Ciudad de México. Cadernos de Saúde Pública, 13:227-236.

ARAÚJO, M. J. O., 1999. Conferência do Cairo - O monitoramento da implementação do Programa de Ação da Conferência de População e Desenvolvimento no Brasil. In: Advocacy em Direitos Reprodutivos e Sexuais. Workshops Nacionais Além do Cairo e de Beijing: Fortalecendo as Organizações de Mulheres no Brasil (Ações em Gênero Cidadania e Desenvolvimento - AGENDE, org.), pp. 56-58, Brasília: AGENDE.

BLANCHET, A. \& GOTMAN, A., 1992. L'enquete et sés méthodes: L'entretien. Paris: Nathan.

CARDICH, R., 1993. Visiones del Aborto: Nexos entre Sexualidad, Anticoncepción y Aborto. Lima: Movimento Manuela Ramos/The Population Council.

CEMICAMP (Centro de Estudos Materno-Infantis de Campinas), 1997. Relatório Final do I Fórum Interprofissional para Implementação do Atendimento ao Aborto Previsto em Lei. São Paulo: Federação Brasileira das Sociedades de Ginecologia e Obstetrícia.

CORRÊA, S., 1999. "Saúde reprodutiva", gênero e sexualidade: Legitimação e novas interrogações. In: Questões de Saúde Reprodutiva (K. Giffin \& S. H. Costa, org.), pp. 39-50, Rio de Janeiro: Editora Fiocruz.

CUNHÃ COLETIVO FEMINISTA, 1997. A História do Abandono - Aborto na Paraíba: A Luta pela Implantação do Serviço de Atendimento aos Casos Previstos na lei. João Pessoa: Cunhã Coletivo Feminista.

DISTRITO FEDERAL, 1996. Resolução do Conselho de Saúde do Distrito Federal no 1/96, de 13 de maio de 1996. Dispõe sobre a criação do Serviço Multiprofissional de Assistência Integral à Mulher, para realização de aborto, nos casos previstos em lei, no Hospital Regional da Asa Sul-HRAS. Brasília: Diário Oficial do Distrito Federal, ano XX, no 91.

D'OLIVEIRA, A. F. \& SCHRAIBER, L. B., 1999. Violência de gênero, saúde reprodutiva e serviços. In: Questões de Saúde Reprodutiva (K. Giffin \& S. H. Costa, org.), pp. 337-355, Rio de Janeiro: Editora Fiocruz.

DREZETT, J., 2000. Aspectos biopsicossociais da violência sexual. Jornal da Rede Nacional Feminista de Saúde e Direitos Reprodutivos, 22:9-12.
GERMAIN, A. \& KIM, T., 1999. Incrementando el Acceso al Aborto Seguro - Estrategias para la Acción. Nova York: International Women's Health Coalition.

GIAMI, A. \& VEIL, C., 1997. Enfermeiras Frente à AIDS, Representações e Condutas, Permanência e Mudanças. Canoas: Editora da ULBRA/Institut National de la Santé et de la Recherche Médicale.

HERZILICH, C., 1991. A problemática da representação social e sua utilidade no campo da doença. Physis, 2:23-36.

MS (Ministério da Saúde), 1999. Norma Técnica de Prevenção e Tratamento dos Agravos Resultantes da Violência Sexual contra Mulheres e Adolescentes. Brasília: MS.

NESP (Núcleo de Estudos de Saúde Pública), 1998. Aborto Legal: As Barreiras Enfrentadas pelas $\mathrm{Mu}$ lheres Vítimas de Estupro no Distrito Federal. Relatório Final. Brasília: NESP, Universidade de Brasília.

PARAÍBA (Estado), 1998. Portaria no 335, de 15 de setembro de 1998. Dispõe sobre a implantação do Programa de Assistência à Mulher Vítima de Violência Sexual e sobre a normatização no serviço público dos casos de abortamento previstos em lei. João Pessoa: Diário Oficial do Estado da Paraíba, 15 set.

RIBEIRO NETO, J. J. A., 2000. Profissional de saúde e o abortamento: É preciso humanizar o atendimento. Jornal da Rede Nacional Feminista de Saúde e Direitos Reprodutivos, 21:6-8.

SCHRAIBER, L. B., 1997. No encontro da técnica com a ética: O exercício de julgar e decidir no cotidiano do trabalho de medicina. Interface - Comunicação, Saúde e Educação, 1:123-140.

SCHRAIBER, L. B. \& D'OLIVEIRA, A. F., 1999. Violência contra mulheres: Interfaces com a saúde. Interface - Comunicação, Saúde e Educação, 5:11-28.

SOUZA, E. B. \& ARAÚJO, J., 2002. Ação pela implantação do Programa de Atendimento a Mulheres Vítimas de Violência Sexual: A experiência da Paraíba. In: Experiências em Advocacy em Saúde e Direitos Sexuais e Reprodutivos (Ações em gênero, cidadania e desenvolvimento - AGENDE, org.), pp. 15-32, Brasília: AGENDE.

Recebido em 5 de junho de 2003

Versão final reapresentada em 17 de novembro de 2003 Aprovado em 28 de novembro de 2003 